\title{
An Observation Account from EFL/ESL Dyads: Code-Switching and Willingness to Communicate
}

\author{
Seyed Yasin Yazdi (Corresponding author) \\ Institute of Research Management and Monitoring \\ Universiti Malaya (UM), Malaysia \\ E-mail: yasin_yazdi@um.edu.my \\ Kamariah Abu Bakar \\ Institute for Mathematical Research, \\ Universiti Putra Malaysia (UPM), Malaysia
}

Received: 04-11- 2013

Accepted: 28-12-2013

Published: 31-01-2014

doi:10.7575/aiac.ijels.v.2n.1p.82

URL: http://dx.doi.org/10.7575/aiac.ijels.v.2n.1p.82

\begin{abstract}
This paper reports a small part of the findings of a larger study which cross-culturally explored and comparatively examined the dynamics of collaboration between Iranian and Malaysian homogeneous dyads during performing collaborative writing tasks. The findings related to the amount of code-switching as well as the amount of falling back on the researcher for language-related assistance in each of the dyads are reported. It was found that while resorting to L1 and willingness to communicate with the researcher was next to nothing in Malaysian dyads, the Iranians had a considerably higher tendency towards using their own language and referring to the researcher for language-related help. The findings are discussed in relation with the previous findings in the related literature.
\end{abstract}

Keywords: willingness to communicate, code-switching and cross-cultural

\section{Introduction}

Along with the studies which have primarily addressed themselves with the cause-effect relationship between collaboration and writing development (e.g., Kuiken \& Vedder, 2002; Storch, 1999, 2005; Shehadeh, 2011), a number of studies in the related literature have looked into the collaborative discourse among the peers while doing group writing. For example, some studies (Lockhart \& Ng, 1995; Mendonca \& Johnson, 1994; Nelson \& Murphy, 1992) have shown that in the course of collaborative engagements for joint writing, L2 learners tend to reflect on different aspects of a text and embark on discussing a variety of textual issues. For instance, Nelson and Murphy (1992) found that during peer response activities a huge portion (i.e., 70\%-80\%) of the discourse exchanged between the interlocutors was related to "the analysis of word order, rhetorical organization, lexical ties, cohesive devices, style, and usage" (p. 187).

There is also a number of studies which have investigated the collaborative dynamics and behaviors of the learners inside the groups while performing collaborative activities. Most of the existing studies in this strand of research have linked the collaboration dynamics inside the groups to the influence of culture (e.g., Donato, 2004; Villamil \& Guerrero, 2006). According to Carson and Nelson (1994, 1996), and Nelson and Carson (1995, 2006), groups should not be seen as culturally neutral and void of cultural connotations in that group dynamics and interactions are influenced by what the members bring with them to the groups. For example, Nelson and Murphy $(1992,1993)$ found that students with different cultural backgrounds had different perceptions and expectations about the group dynamics, politeness strategies, etc. In their investigation of interaction in peer response groups, Carson and Nelson (1996) and Nelson and Carson(1998) came up with a surprising amount of similarity in the perceptions and behaviors of three female Chinese students in three different peer response groups. For example, they were found to be reluctant to criticize others' drafts reasoning that they did not intend to embarrass the writer. Hyland (2000) and Hyland (2003) have reported similar behaviors among Chinese and Hong Kongers and have attributed the lack of negative feedback among them to cultural issues. Nelson and Carson (2006) hypothesize that the behaviors of people in the groups are the reflections of their cultural backgrounds. A study by Ellis and Gauvain (1992) even showed a discrepancy in the behaviors and the intersubjectivity (i.e., the construction of shared meanings and concepts) of children who were affiliated with different cultural backgrounds. They comparatively observed Navajo children as opposed to EuropeanAmerican children. The observation found that pairs of nine-year-old Navajo children who were supposed to teach seven-year-olds to play a game were much more willing to build on each other's comments than were EuropeanAmerican children. Furthermore, the contrastive observation of the children's behaviors indicated that while the Navajo children remained engaged in observing their partners when they were not controlling the game moves, the EuropeanAmerican children lost their interest and they sometimes even left the tasks when they found themselves not in the 
control of the game any longer. The researchers attributed the discrepancy in the children's behaviors to the variable of their cultural background.

Drawing upon the findings and the suggestions of the previous studies which have all reiterated the relationship between cultural background of the group members and collaboration dynamics inside the group, this study set out to shed light on the interactive behaviors of Malaysian and Iranian dyads with regard to their amount of shifting to their L1 as well as referring to the researcher for the language-related help during performing collaborative writing tasks.

\section{Methodology}

\subsection{Participants}

Participants of the study were eight homogeneous female Iranian and Malaysian undergraduate students at a private university in Kuala Lumpur who were divided into two Iranian dyads (A \& B) and two Malaysian dyads (dyad C \& D). The pseudonyms used for the participants were: Azadeh and Sadaf (Dyad A), Negar and Niloufar (Dyad B), Mei and Tang (Dyad C), and Gin and Wai (Dyad D). It is necessary to note that homogeneity of the participants refers to the sameness of their English proficiency, gender, and academic discipline.

The participants in each dyad performed fifteen writing tasks (IELTS Academic Module task 1) collaboratively. They were encouraged to converse in English and not to resort to their L1 as much as possible. "Acquaintanceship" and level of social relations and cordiality between the dyad members (O'Sullivan, 2002) as well as between the participants and the researcher (Donato, 2004) were taken care of. Based on the results of O'Sullivan's (2002) study on Japanese ESL learners' pair-task performance on an oral proficiency test, it has been recommended that the dyads should be configured in such a way that all members be either friends or strangers. In O'Sullivan's study, the participants achieved higher test scores in terms of accuracy when working with a friend than with a stranger. In the present study, the peers in each dyad knew each other. As for the level of social intimacy between the researcher and participants, Donato (2004) stresses the "importance of time required to establish social relations necessary for collaboration" (p. 287). Thus, a time-span of three weeks was allocated so that participants and also the researcher could establish some rapport and cordiality. In order to fulfill this requirement of the study, the researcher invited the participants out (i.e., coffee shop, and the university canteen) a few times. The modus operandi seemed quite effective as a good rapport was evidently built up among the entire research group.

\subsection{Data Collection Procedure}

The researcher took observation notes whilst the students were engaged in collaborative writing, paying attention to the participants' amount of resorting to their L1 and their willingness to communicate with the researcher. It should also be pointed out that all collaborative writing sessions were audio-video recorded in order to capture all the possible points and hints which the researcher might have missed during his observations. The video recorded data could in fact provide the researcher with more contextual data and it could help the researcher to see the activities repeatedly by playing it back.

\section{Findings and Discussion}

Observing the collaborative sessions and reviewing the recorded films of the sessions (by the researcher himself and another PhD student of TESL) revealed fundamental differences between Iranian dyads (A\& B) and Malaysian dyads (C\& D) in terms of the amount of using L1 and referring to the researcher for language-related help during the entire collaborative sessions. Unlike Malaysian participants among whom code-switching was next to nothing and all the collaborative discourse took place in English, switching to L1 was quite noticeable among Iranians despite the fact that the peers enjoyed an acceptable level of L2 competency. Sadaf (dyad A) had a stronger tendency to switch to Farsi. The researcher initially speculated that the most important reason for her higher frequency of code-switching could be due to her difficulty with putting her meanings across through English. However, Sadaf provided a completely different reason. She appeared to have perceived her English conversations with her peer (a non-native speaker) as a sort of unauthentic and artificial and commented that:

It is strange and hard to speak English with your friend. It is not [doesn't look] natural.... When you speak English with an English or an American person, it is different; it is natural; but when you speak English with your friend only for doing a writing, I can't see it serious[can't take it seriously]...

Kang (2005), who conducted a small-scale study with four Korean students to search for the affective factors related to willingness to communicate (WTC), reports that learners commented about their reluctance to speak in the L2 in groups composed of fellow L1 speakers. One participant blamed his reluctance to speak L2 on the 'unnatural' situation: "I feel like I'm wearing a mask" (p. 284). According to the researcher, whether or not the learners' interlocutors were native speakers or non-native speakers [Korean] affected their level of "excitement." In other words, the participants perceived talking to a native speaker more exciting. By "excitement" it was meant "...a feeling of elation about the act of talking" (p. 284). Similarly, Leger and Storch (2009) reported "perceived lack of authenticity of small group discussion" (p. 279) as a reason behind the unwillingness of some students to interact in the L2 with their peers. They reported that one of the students commented that "it is hard to keep speaking in French when there is no natural born French speaker there to help" (p. 279).

Similarly, in dyad B, Niloofar and Negar tended to switch to their L1, especially in the moments of argument and discussing grammatical jargons. Negar argued that as they were pressed for time, using mother tongue was a short-cut to put their meaning across with the least likelihood of misunderstanding. Niloofar said she did not have difficulty 
explaining herself in English, but she sometimes just found it pointless and boring to consume lots of energy to talk about the task and particularly grammar. Based on the findings of Kang's (2005) study, the desirability of the topic was one of the factors that affected the participants' feeling of excitement. According to the researcher, "The participants tended to be excited to talk while talking about topics in which they were interested..." (p. 284). However, in the present study it seemed to be otherwise because as Niloofar pointed out she obviously did not have any interest in talking about grammar in L2.

The tendency of Iranian participants of the study to make a frequent use of their mother tongue during collaborative sessions is in contrast to the findings of previous studies on the use of L1 by Iranian students. For example, the findings of some studies (e.g., Mahmoudi \& Yazdi Amirkhiz, 2011; Nazary, 2008) carried out in Iranian context indicated that despite a predominant use of L1 in English classes in schools of Iran, students were supportive of L2 domination in their English classes. Also, more relevant to add here are the findings of Storch and Aldosari's (2010) study. The researchers particularly investigated the effect of learner proficiency pairing (High-High, High-Low, and Low-Low) and task type on the amount of L1 used by learners of English as a foreign language (EFL) during pair work. The researchers found that "there was a modest use of L1 in pair work activity and that task type had a greater impact on the amount of L1 used than proficiency pairing" (p. 355). Their findings are in part similar to the findings of the present study. As far as the use of L1 by EFL learners (Iranians in the present study and Arabs in Storch and Aldosari's study) are concerned, the findings are almost the same; that is, EFL learners used L1 during pair work. However, in the present study when it comes to a comparison of L1 use between Malaysian (ESL) and Iranian (EFL) participants, the scenario completely changes. Malaysian and Iranian participants were of similar level of language proficiency and dealt with the identical tasks, but they did have a totally different amount of L1 use in their pair talk; Iranians' use of L1 was considerably high whereas Malaysians' using their mother tongue was next to nothing. Whether the similarity in L1 use of Iranians and Arabs (EFL) and the difference between Iranian (EFL) and Malaysian (ESL) participants (in terms of use of L1) have anything to do with the status of the English language, being EFL for Iranians and ESL for Malaysians, it remains a speculation that awaits further exploration.

Another possible explanation for the lack of code-switching among Malaysian participants might be that as the students knew they were under research condition (observation), they might have taken the deliberate choice not to use their L1 in order to let the researcher, who was sitting next to them, comprehend their pair talk and take notes of their collaboration process. This might not have been the case with Iranians because they knew that the researcher shared their mother tongue and alternating between either of the languages (their L1 \& English) would not hamper the process of data collection by the researcher.

Another frequent event during collaborative sessions was a tendency of Iranian peers to refer to the researcher for language-related help. On many occasions when they ran out of ideas or were not confident enough about their linguistic choices, they often turned to researcher as a reliable source for an appropriate phrase or word or structure. This frequent falling back on researcher's suggestion was apparently an indication that the peers did not consider themselves as a reliable and safer source of mistake correction. One possible explanation might be the teacherdependency of Iranian students. In support of such a tendency, Rabiee (2008) came up with similar findings. She includes the following sentiments from a couple of her Iranian students who were involved in a peer response activity.

I would like to receive comments from teacher because, s/he is more reliable and I know the mistake [that] is corrected by her is right. Sometimes this mistake which is corrected by classmates should be corrected by teacher again (p.13).

This activity taught me to think before writing on paper. It would be better if more time we had and teacher controlling our comments (p. 13).

Contrary to Iranians, Malaysian participants of the study seemed self-reliant and apparently resolved all languagerelated problems inside the dyad, because there was not even one single instance of referring to the researcher for any sort of feedback or support throughout the collaborative writing sessions. One might attribute the behavior to the lack of social intimacy between the researcher and the Malaysian participants. However, as it was stated earlier, in order to address the acquaintanceship effect which is deemed to affect studies of qualitative nature, the researcher invited all the participants to a restaurant and coffee shops in order to establish some kind of rapport. In fact, the researcher and the participants had achieved a good level of social intimacy within the three-week period (familiarization period) prior to data collection. Therefore, the possibility of shyness being the sole reason behind the Malaysians' unwillingness to turn to the researcher could be ruled out and other factors come to the picture. Such a behavior might have been an indication of students' deference towards the teacher. According to Scollon (1994), as a result of the influence of Confucian ethics or ideological beliefs, students in East Asia feel obliged to have respect for authority (e.g. parents and teachers) and they hardly question the authority. Alluding to the findings of other studies, Hofstede (1986) asserted that students from collectivist cultures only speak when addressed.

\section{References}

Carson, J. G., \& Nelson, G. L. (1994). Writing groups: Cross-cultural issues. Journal of Second Language Writing, 3(1), 17-30.

Carson, J. G., \& Nelson, G. L. (1996). Chinese students' perceptions of ESL peer response group interaction. Journal of Second Language Writing, 5(1), 1-19. 
Donato, R. (2004). Aspects of collaboration in pedagogical discourse. Annual Review of Applied Linguistics, 24, 284302.

Hofstede, G. (1986). Cultural differences in teaching and learning. International Journal of Intercultural Relations, 10(3), 301-320.

Hyland, F. (2000). ESL writers and feedback: Giving more autonomy to students. Language Teaching Research, 4(1), 33.

Hyland, K. (2003). Second language writing: Ernst Klett Sprachen.

Kang, S. J. (2005). Dynamic emergence of situational willingness to communicate in a second language. System, 33(2), 277-292.

Kuiken, F., \& Vedder, I. (2002). Collaborative writing in L2: The effect of group interaction on text quality. Rijlaarsdam, Gert (Series Ed.), Ransdell, Sarah \& Marie-Laure Barbier (Vol. Eds) Studies in Writing, 11, 169-188.

Leger, D. S., \& Storch, N. (2009). Learners' perceptions and attitudes: Implications for willingness to communicate in an L2 classroom. System, 37(2), 269-285.

Lockhart, C., \& Ng, P. (1995). Analyzing talk in ESL peer response groups: Stances, functions, and content. Language Learning, 45(4), 605-651.

Mahmoudi, L., \& Yazdi Amirkhiz, S. Y. (2011). The use of Persian in the EFL classroom: The case of English teaching and learning at pre-university level in Iran. English Language Teaching, 4(1), p135.

Mendonca, C. O., \& Johnson, K. E. (1994). Peer review negotiations: Revision activities in ESL writing instruction. TESOL Quarterly, 745-769.

Nazary, M. (2008). The role of L1 in L2 acquisition: Attitudes of Iranian university students. Novitas-Royal, 2(2), 138153.

Nelson, G. L., \& Carson, J. G. (2006). Cultural issues in peer response:Revisiting "culture". . In K. Hyland \& F. Hyland (Eds.), Feedback in second language writing: Contexts and issues (pp. 42-59). Cambridge: Cambridge University Press.

Nelson, G. L., \& Carson, J. G. (1995). Social dimensions of second-language writing instruction: Peer response groups as cultural context. In D. Rubin (Ed.), Composing social identity in written language (pp. 89-109). Hillsdale, NJ: Lawrence Erlbaum.

Nelson, G. L., \& Murphy, J. M. (1992). An L2 writing group: Task and social dimensions. Journal of Second Language Writing, 1(3), 171-193.

O'Sullivan, B. (2002). Learner Acquaintanceship and Oral Proficiency Test Pair-Task Performance. Language Testing, 19 (3), 277-295

Rabiee, M. (2008). Grouping students in peer response: The Iranian EFL students' attitudes toward dyadic grouping in writing classes. Paper presented at the Asia TEFL Conference.

Scollon, R. (1994). Post-Confucian Confusion. Hong Kong: City University of Hong Kong, Dept. of English.

Shehadeh, A. (2011). Effects and student perceptions of collaborative writing in L2. Journal of Second Language Writing.

Storch, N. (1999). Are two heads better than one? Pair work and grammatical accuracy. System, 27(3), 363-374.

Storch, N. (2005). Collaborative writing: Product, process, and students' reflections. Journal of Second Language Writing, 14(3), 153-173.

Storch, N., \& Aldosari, A. (2010). Learners' use of first language (Arabic) in pair work in an EFL class. Language Teaching Research, 14(4), 355.

Villamil, O. S., \& Guerrero, M. (2006). Sociocultural theory: A framework for understanding the social-cognitive dimensions of peer feedback. Feedback in second language writing: Contexts and issues, 23-42. 